\title{
NATURAL SELECTION AND CYANOGENESIS IN WHITE CLOVER, TRIFOLIUM REPENS
}

\author{
J. A. BISHOP and M. E. KORN \\ Departments of Genetics and Zoology, The University of Liverpool
}

Received 10.x.68

\section{INTRODUGTION}

THE foliage of many species of plant produces hydrogen cyanide after undergoing mechanical damage. This poisonous substance is generated in small quantities by the hydrolysis of cyanogenic glucosides that takes place after the damage occurs. Production of these glucosides is under genetic control, and in white clover, Trifolium repens $\mathrm{L}$. depends on the presence of a single dominant allele $A c$ ( $a c$ is acyanogenic). Rate of generation is influenced by an enzyme, linamarase which speeds the breakdown of the glucosides (Coop, 1940). The production of this enzyme requires the presence of a further dominant allele $L i$ ( $l i$ lacks the enzyme) located on a different chromosome to the glucoside locus (Corkill, 1942). The possible genotypic combinations and their phenotypes are listed in table 1. Wild populations of T. repens are frequently polymorphic at both loci (Daday, 1954a).

Plants that produce $\mathrm{HCN}$ rapidly give a positive response to the Guignard picrate paper test (Corkill, 1940) within 2 hours. The slow producers take up to 24 hours to give a positive response.

Daday (1954a) found a close correlation in European populations of $T$. repens between the frequency of $A c$ and $L i$ and January temperatures. Frequency of both alleles was highest near the Mediterranean and lowest in inland areas of northern Europe. Similarly, frequency of $A c$ and $L i$ decreased with altitude in the Alps (Daday, 1954b). A parallel reduction in the quantity of HCN produced by cyanogenic plants indicates the probable influence of modifier genes. Daday (1965, and in preparation) found that cold temperatures activated linamarase and the HCN produced irreversible inhibition of the respiratory system of the $A c L i$ genotype causing tissue death. Acyanogenic forms were thus left at a corresponding advantage. The balancing selective forces are not as well understood; two suggestions have been made which merit further consideration.

Jones (1962, 1966) investigated cyanogenesis in the bird's-foot trefoil, Lotus corniculatus $\mathrm{L}$. and found evidence that the vole Microtus agrestis $(\mathrm{L})$, the snails Arianta arbustorum (L) and Helix aspersa Muller, and the slug Agriolimax reticulatus Muller ate acyanogenic or slightly cyanogenic plants in preference to more strongly cyanogenic ones. He concluded that cyanogenesis was a defence mechanism which discouraged animals from eating $L$. corniculatus, and suggested that this was also true of $T$. repens. Jones further suggested that January temperatures control the distribution of animals that selectively eat the acyanogenic plants, giving rise to the temperature correlations discussed in the previous paragraphs. This last suggestion seems unlikely in the light of Daday's (1965) findings. 
Daday (1965) found cyanogenesis to be associated with greater " physiological and morphological fitness" in warm climates. The polymorphism for the glucoside and linamarase loci was associated with polymorphism for polygenic physiological and morphological fitness characters.

The selective forces proposed by Jones $(1962,1966)$ requires there to be preferential eating of acyanogenic clover by herbivores. We investigated this. possible mechanism of selection under greenhouse conditions, using the snail Helix aspersa and the slug Agriolimax reticulatus as experimental subjects. Jones had used both these species in his experiments and concluded that they discriminated between acyanogenic and cyanogenic $L$. corniculatus.

TABLE 1

Possible genotypic combinations at the glucoside and linamarase loci in Trifolium repens and their phenotypes

$\left.\begin{array}{lr} & \text { Genotype } \\ A c / A c & L i / L i \\ A c / A c & L i / l i \\ A c / a c & L i / L i \\ A c / a c & L i / l i \\ A c / A c & l i / l i \\ A c / a c & l i / l i\end{array}\right\} \quad$ Phenotype

Any such differential eating must result either from a chemical sensitivity to the glucoside or the released cyanide (whether the rejection be innate or a learned response) or from reduced eating by a snail that has begun to browse a cyanogenic plant, as a result of the toxic effects of cyanide. We sought also to investigate whether there was any sensory discrimination. The site of chemical sensitivity in Helix aspersa is uncertain. The main site of distant chemosensitivity (smell) is believed to be the posterior tentacle, which also bears the eye. Contact chemoreception (taste) is more widely distributed in the epidermis of the head, the anterior tentacles and the oral lappets being especially sensitive. Removal of the posterior tentacles reduces. the distance at which a snail can perceive an odoriferous substance; removal of all four tentacles abolishes distance sensitivity, but contact sensitivity remains. Removal of the oral lappets increases the threshold above which substances are detected, but does not abolish the response completely (Kieckebush, 1953).

\section{EXPERIMENTS}

Trifolium repens was obtained from the University of Liverpool Botanic Gardens at Ness, Cheshire, where it grows as a weed. Fifty plants were collected, potted, and later scored using the Guignard test (Corkill, 1940); only rapid producers of HCN which gave a strong response (glucoside score 5 or 6 (Jones, 1966)) were used as cyanogenic plants. Mature Helix aspersa came from Meols, Cheshire and Blockley, Gloucestershire; immature animals were collected in Pembrokeshire. Agriolimax reticulatus was obtained from greenhouses in the Liverpool area. Before the experiments, animals 
were kept in plastic lunch boxes and fed with cabbage leaves. The temperature in the greenhouse where experiments were performed was kept in the range $15^{\circ}-20^{\circ} \mathrm{C}$.

\section{Experiment 1}

The object of this was to determine whether $H$. aspersa discriminates between acyanogenic and cyanogenic clover and if so, whether the sense organs involved are located in either pair of tentacles-the anterior or the posterior (optic) tentacles. Twelve cyanogenic and twelve acyanogenic plants with 100-200 leaves each were sorted into four groups with three plants of each type. We both independently counted the leaves on each plant without knowing its phenotype. The pots in each group were arranged at random in a circle in a large aquarium tank. John Innes compost was packed around the pots until its surface was level with their tops.

Four groups of six $H$. aspersa were treated in the following way: the anterior tentacles were removed from one, the posterior from a second, both pairs of tentacles were removed from the third group and the fourth was left intact. One group was then placed in each of the experimental containers, which were watered and partly covered by glass plates to keep the humidity as high as possible. After four days, the snails were removed, the leaves counted again and the differences in numbers calculated. Plants were watered daily. This process was repeated four times; the plants were redistributed at random on each occasion, and the snails were moved from one container to the next in sequence. The entire experiment was designed so that results were amenable to treatment by the analysis of variance technique.

\section{Experiment 2}

This experiment aimed at determining whether Agriolimax reticulatus discriminates between acyanogenic and cyanogenic clover and was similar to the previous one, though intact animals only were used. Fifty $A$. reticulatus were used. Four plants of each type that were smaller (50 leaves) than those used in experiment l were presented. There were six blocks each of six days' duration.

\section{Experiment 3}

The results of experiments 1 and 2 may be invalidated whatever the conclusion they support if one type of clover grows or regenerates faster than the other. To see if this was so a number of clover plants were allowed to grow without being exposed to the herbivores. Leaves were counted every three days and the data obtained was incorporated into an analysis of variance.

\section{Experiment 4}

If snails discriminate between acyanogenic and cyanogenic clover this is presumably because it is to their advantage to do so. Those snails that eat cyanogenic clover may be placed at a disadvantage either by the direct effect of HCN on their respiration or because the HCN inhibits the cellulaseproducing micro-organisms that occur in their alimentary tracts and which 
TABLe 2

Analysis of variance for an experiment testing the effect of three factors (surgical operation, cyanogenesis and experimental block number) on consumption of leaves of Trifolium repens by the snail, Helix aspersa. (1) J.A.B. counts; (2) M.E.K. counts.

\begin{tabular}{|c|c|c|c|c|c|}
\hline \multirow[b]{2}{*}{ Source } & \multirow{2}{*}{$\begin{array}{l}\text { Degrees of } \\
\text { freedom }\end{array}$} & \multicolumn{2}{|c|}{ Mean square } & \multicolumn{2}{|c|}{ F. } \\
\hline & & (1) & (2) & (1) & (2) \\
\hline $\begin{array}{l}\text { Operations }(A) \\
\text { Cyanogenic/Acyanogenic }(B) \\
\text { Blocks }(C)\end{array}$ & $\begin{array}{l}3 \\
1 \\
3\end{array}$ & $\begin{array}{r}8127 \\
486 \\
5097\end{array}$ & $\begin{array}{r}12311 \\
376 \\
11342\end{array}$ & $\begin{array}{l}7 \cdot 09^{* * *} \\
0 \cdot 42 \\
4 \cdot 45^{* *}\end{array}$ & $\begin{array}{l}14 \cdot 45^{* * *} \\
0 \cdot 44 \\
13 \cdot 31^{* * *}\end{array}$ \\
\hline $\begin{array}{l}\text { Interaction }(A B) \\
\text { Interaction }(B C) \\
\text { Interaction }(A C)\end{array}$ & $\begin{array}{l}3 \\
3 \\
9\end{array}$ & $\begin{array}{l}1529 \\
1284 \\
2686\end{array}$ & $\begin{array}{r}3266 \\
772 \\
1484\end{array}$ & $\begin{array}{l}1 \cdot 33 \\
1 \cdot 12 \\
2 \cdot 35\end{array}$ & $\begin{array}{l}3.83^{*} \\
0.91 \\
1 \cdot 74\end{array}$ \\
\hline Interaction $(A B C)$ & 9 & 436 & 2816 & $0 \cdot 38$ & $3 \cdot 30$ \\
\hline Error & 64 & 1145 & 852 & & \\
\hline
\end{tabular}

Mean number of leaves eaten (I) $\mathcal{F}$.A.B. counts

Acyanogenic

Posterior Anterior Both pairs

Block No. Unoperated tentacles tentacles of tentacles Total

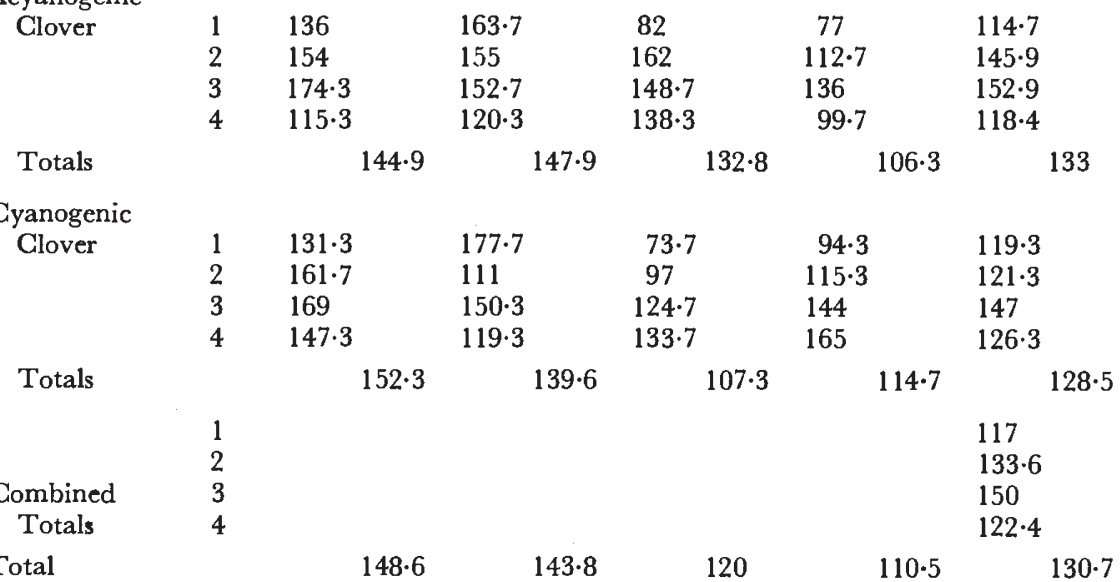

Mean Number of leaves eaten (2) M.E.K. counts

\begin{tabular}{|c|c|c|c|c|c|c|}
\hline & Block No. & Unoperated & $\begin{array}{l}\text { Posterior } \\
\text { tentacles }\end{array}$ & $\begin{array}{l}\text { Anterior } \\
\text { tentacles }\end{array}$ & $\begin{array}{l}\text { Both pairs } \\
\text { of tentacles }\end{array}$ & Total \\
\hline $\begin{array}{l}\text { Acyanogenic } \\
\text { Clover }\end{array}$ & $\begin{array}{l}1 \\
2 \\
3 \\
4\end{array}$ & $\begin{array}{c}142 \\
85 \\
169 \\
89 \cdot 7\end{array}$ & $\begin{array}{l}135 \cdot 3 \\
111 \\
175 \\
78\end{array}$ & $\begin{array}{c}65 \cdot 7 \\
123 \\
105 \\
89 \cdot 7\end{array}$ & $\begin{array}{l}48 \cdot 7 \\
78 \cdot 3 \\
93 \\
70 \cdot 3\end{array}$ & $\begin{array}{r}97.9 \\
99.3 \\
134.5 \\
81.9\end{array}$ \\
\hline Totals & & $120 \cdot 4$ & $124 \cdot 8$ & $95 \cdot 8$ & $72 \cdot 6$ & $103 \cdot 4$ \\
\hline $\begin{array}{l}\text { Cyanogenic } \\
\text { Clover }\end{array}$ & $\begin{array}{l}1 \\
2 \\
3 \\
4\end{array}$ & $\begin{array}{l}106 \\
157 \cdot 3 \\
165 \cdot 3 \\
127\end{array}$ & $\begin{array}{c}101 \cdot 3 \\
86 \cdot 7 \\
105 \\
77 \cdot 7\end{array}$ & $\begin{array}{c}42 \cdot 7 \\
85 \\
114 \cdot 7 \\
86 \cdot 3\end{array}$ & $\begin{array}{c}63 \cdot 7 \\
65 \cdot 7 \\
140 \\
67\end{array}$ & $\begin{array}{r}78 \cdot 4 \\
98 \cdot 7 \\
131 \cdot 3 \\
89.5\end{array}$ \\
\hline Totals & & 138.9 & $92 \cdot 7$ & $82 \cdot 2$ & $84 \cdot 1$ & $99 \cdot 5$ \\
\hline $\begin{array}{l}\text { Combined } \\
\text { Totals }\end{array}$ & $\begin{array}{l}1 \\
2 \\
3 \\
4\end{array}$ & & & & & $\begin{array}{c}88 \cdot 2 \\
99 \\
132 \cdot 9 \\
85 \cdot 7\end{array}$ \\
\hline Total & & $129 \cdot 7$ & $108 \cdot 8$ & 89 & $78 \cdot 3$ & $101 \cdot 4$ \\
\hline
\end{tabular}


supplement the snails' own production of this enzyme (Vonk, 1964,pp. 385-7). If this is so it is possible that snails fed only acyanogenic clover would grow faster than those fed only cyanogenic clover.

The maximum height, maximum width and whorl number of the shells of a number of immature Helix aspersa was measured. The snails were then sorted into pairs of similar size and one member of each pair was fed on cyanogenic and the other on acyanogenic clover. Pieces of limestone were placed in each pot as a possible source of extra calcium for shells. The shells were measured again at intervals of 14 days during the experiment, and results were rejected if the snail had matured during the previous fourteen days. (Maturity was assumed to coincide with the formation of a lip at the shell aperture.) Results were incorporated into a single-factor analysis of variance.

\section{Experiment 1}

\section{Results}

Results are presented in table 2. Two of the three factors tested (effect of surgery and blocks) significantly influenced the amount of leaves that the snails ate. Snails however did not discriminate between cyanogenic and acyanogenic clover. The removal of the posterior (optic) tentacles alone did not effect the amount of eating, but those that had the anterior tentacles removed ate fewer leaves than those that had only the optic tentacles removed and those that had been left intact. There was no significant further reduction when both pairs of tentacles were removed. This indicates that the anterior tentacles play some part in feeding but not in discrimination.

\section{Experiment 2}

The analysis of variance for this experiment is given in table 3 . The slugs did not discriminate between acyanogenic and cyanogenic clover though differences between blocks were significant.

\section{TABLE 3}

Analysis of variance for an experiment testing the effect of two factors (cyanogenesis and experimental block number) on consumption of leaves of Trifolium repens by the slug Agriolimax reticulatus

$\begin{array}{lcccc}\text { Source } & \text { Sum of squares } & \text { Degrees of freedom } & \text { Mean square } & \text { F } \\ \text { Cyanogenic/Acyanogenic } & 19 & 1 & 19 & 0 \cdot 28 \\ \text { Blocks } & 1198 & 5 & 240 & 3 \cdot 33^{*} \\ \text { Interaction } & 181 & 5 & 36 & 0 \cdot 50 \\ \text { Error } & 2582 & 36 & 72 & \\ \text { Total } & 3980 & 47 & \end{array}$

* $\mathrm{P}<0 \cdot 05$, other $\mathrm{F}$ values not significant.

\section{Experiment 3}

The analysis of variance (table 4) shows that there is no differential growth between acyanogenic and cyanogenic plants in the absence of snails or slugs. The results of experiments 2 and 3 are therefore uncomplicated by any differential growth of the two types of clover. (It remains possible that acyanogenic plants replace grazed leaves faster than cyanogenic, thereby masking any difference in grazing.) 
TABLE 4

Analysis of variance for an experiment comparing rate of leaf production in acyanogenic and cyanogenic Trifolium repens

$\begin{array}{lcccc}\text { Source } & \text { Sum of squares } & \text { Degrees of freedom } & \text { Mean square } & \text { F } \\ \text { Cyanogenic/acyanogenic } & 203 & 1 & 203 & 2 \cdot 18 \\ \text { Blocks } & 2557 & 4 & 639 & 6 \cdot 87 * \\ \text { Interaction } & 474 & 4 & 119 & 1 \cdot 28 \\ \text { Error } & 2794 & 30 & 93 & \\ \text { Total } & & 39 & & \end{array}$

* $\mathrm{P}<0 \cdot 005$, other $\mathrm{F}$ values not significant.

\section{Experiment 4}

Table 5 shows no evidence of there being differential growth in snails fed on acyanogenic clover and snails fed on cyanogenic clover. The shells of both groups of snails grew to an equal extent.

TABLE 5

Analysis of variance for an experiment to test the effect of cyanogenic clover on three parameters of growth in the snail, Helix aspersa

(a) Height

$\begin{array}{llrll}\text { Main effect } & 0.0138 & 1 & 0.0138 & 0.2494 \\ \text { Error } & 0.6611 & 14 & 0.0472 & \\ \text { Total } & 0.6749 & 15 & & \end{array}$

(b) Width

$\begin{array}{lrrrr}\text { Main effect } & 0.0105 & 1 & 0.0105 & 0.2756 \\ \text { Error } & 0.5333 & 14 & 0.0381 & \\ \text { Total } & 0.5438 & 15 & & \end{array}$

(c) Whorl number

Main effect

Error

0.0600

0.6198

0.0600

$1 \cdot 3544$

Total

0.6798

$14 \quad 0.0443$

15

* No F value significant.

\section{Discussion}

These results suggest that cyanogenesis of $T$. repens does not deter the two herbivores Agriolimax reticulatus and Helix aspersa. Therefore, they do not support any hypothesis which states that selection against cyanogenic clover at low temperature is balanced by the selective feeding activity of herbivores. More experiments under field conditions are required to put the matter beyond reasonable doubt though Jones (personal communication) found that these herbivores discriminated between cyanogenic and acyanogenic $L$. corniculatus both under greenhouse conditions and in outdoor enclosures. $T$. repens however contains less cyanide per gram than $L$. corniculatus (Jones, 1966; Corkill, 1952).

Ford (1963) and Pusey (1963) did not base statements concerning discrimination by herbivores on experiments done on $T$. repens. They left their 
readers to take the step from $L$. corniculatus to $T$. repens themselves. This step is unjustifiable on evidence at present available and it is important that this be pointed out in view of the prominence now being given to this supposed example of natural selection in senior secondary school courses.

Sheep do not discriminate between cyanogenic and acyanogenic $T$. repens; nor was there any difference in production of the two types of clover in agricultural field trials (Corkill, 1952). The results of our smaller scale experiments were fully in keeping with this. Corkill estimates that very strongly cyanogenic clover contains 0.035 per cent. HCN which is released more or less rapidly depending on whether linamarase is present. This concentration does not approach the level which is toxic to sheep $(0.09$ per cent.). Similar data for herbivorous gastropods are not available though the results presented above suggest that the HCN from clover has little or no deleterious effects on their metabolism. Snails fed only cyanogenic clover for several months showed no obvious ill effects and did not lose weight compared with control animals fed only acyanogenic clover (Bishop and Korn, unpublished).

Daday (1965) suggests that the role of the glucoside and the linamarase loci may have been enhanced by accretion of linked loci affecting asexual and sexual efficiency. Further he suggests that during this process genes enhancing fitness at high or low temperatures have become linked with the dominant and recessive alleles respectively. It is a truism that natural selection favours the fittest phenotypes and since fitness is closely related to reproductive success the entire genotype represents an accretion of linked loci conferring the greatest efficiency in reproduction both sexual and asexual. It seems unlikely that under these circumstances a clover plant will have a glucoside gene inserted into an unrelated genetic background.

The glucoside and linamarase loci are unlinked in $\mathcal{T}$. repens. The alleles have existed for a considerable time and are common amongst clovers and related plants. There has been plenty of time for a supergene to evolve as one would expect if cyanogenesis was a defence mechanism. Thus Daday's (1965) proposals concerning the selective forces balancing the effect of frost damage in cyanogenic plants seem to be the most likely.

Cytological studies (Brewbecker and Keim, 1953) show T. repens to be an amphidiploid with Trifolium nigrescens Viv, as one of the ancestors. $T$. nigrescens occurs in southern Europe and Asia Minor. Daday (1965) reports it to be strongly cyanogenic. He examined four populations but found no polymorphism at either the glucoside or the linamarase locus. If $T$. nigrescens is polymorphic at these loci it would be useful to repeat experiments 1 to 4 to see whether, in this case, herbivores discriminate. Perhaps when the amphidiploid arose the degree of cyanogenesis was reduced allowing the new species to spread into areas of Europe subject to more severe frosts. This reduced level of cyanogenesis may no longer be a deterrent to herbivores but it may allow cyanogenic plants to resist rusts or other fungal pathogens thus increasing their fitness relative to the acyanogenic forms. This problem would be clarified if the second ancestor species were to be discovered and selected characteristics of all three species investigated.

\section{Summary}

1. Many populations of $T$. repens are polymorphic for cyanogenesis. Whereas it has been shown that one selective force is associated with greater 
susceptibility to frost damage of cyanogenic plants, the balancing selection is less well understood. Some workers suggest that cyanogenesis offers protection against herbivores, others that it is associated with a greater fitness in warm climates.

2. Our experiments showed no significant difference in the quantities of cyanogenic and acyanogenic clover eaten by the snail, Helix aspersa, and the slug, Agriolimax reticulatus, under greenhouse conditions.

3. There was no significant difference between the rates of growth of the two types of $T$. repens, such as might mask a difference in herbivoration.

4. There was no significant difference between the rate of growth of $H$. aspersa fed exclusively on cyanogenic, and that fed exclusively on acyanogenic clover, as shown by measurements of shell height, shell width, and number of whorls.

5. Since there is no evidence of discrimination by herbivores, it seems likely that the balancing selective factor is concerned with greater physiological fitness.

Acknowledgments.-We wish to thank Professor P. M. Sheppard, F.R.S., for stimulating and encouraging this study. We have benefited from discussions with Professor A. D. Bradshaw, Professor A. J. Cain, Dr D. A. Jones, and colleagues in Liverpool and Manchester. Part of the work was carried out while one of us (J. A. B.) was a Commonwealth Scholar.

\section{REFERENCES}

BreWbecker, J. L., AND KeIM, W. F, 1953. A fertile interspecific hybrid in Trifolium. Am. Nat., 87, 323-326.

COOP, I. E. 1940. Cyanogenesis in white clover (Trifolium repens L.). III. A study of linamarase, the enzyme which hydrolyses lotaustralin. N. Z. F. Sci. Tech., 22, 71в-83в.

CORKILL, L. 1940. Cyanogenesis in white clover (Trifolium repens L.). I. Cyanogenesis in single plants. N.Z. F. Sci. Tech., 22, 65в-67в.

CORKILI, L. 1942. Cyanogensis in white clover (Trifolium repens L.). V. The inheritance of cyanogensis. N. Z. J. Sci. Tech., 23, 178в-193в.

CORKILL, L. 1952. Cyanogenesis in white clover (Trifolium repens L.). VI. Experiments with high glucoside, and glucoside-free strains. N.Z. F. Sci. Tech., 34, 1A-16A.

DADAY, H. 1954a. Gene frequencies in wild populations of Trifolium repens. $L$. I. Distribution by latitude. Heredity, 8, 61-78.

DADAY, H. 1954b. Gene frequencies in wild populations of Trifolium repens $L$. II. Distribution by altitude. Heredity, $8,377-384$.

DADAY, H. 1965. Gene frequencies in wild populations of Trifolium repens $L$. IV. Mechanisms of natural selection. Heredity, 20, 355-365.

FORD, E. B. 1964. Ecological Genetics. Methuen, London.

JONES, D. A. 1962. Selective eating of the acyanogenic form of the plant Lotus corniculatus $L$. by various animals. Nature, 193, 1109-1110.

JONES, D. A. 1966. On the polymorphism of cyanogenesis in Lotus corniculatus L. I. Selection by animals. Can. F. Genet. Cytol., 8, 556-567.

KIEckebush, w. 1953. Beitrag zur Physiologie des chemischen Sinnes von Helix pomatia. Zool. Fhb. Abt. Allg. Zool. u. Physiol. d.T. 64.

Pusey, J. G. 1963. Cyanogenesis in Trifolium repens in Teaching Genetics (C. D. Darlington and A. D. Bradshaw, eds.) Oliver and Boyd, Edinburgh.

voNK, H. J. 1964. Comparative biochemistry of digestive mechanisms in Comparative Biochemistry (F. Florkin and H. S. Mason, eds.) Academic Press, London, Vol. VI, 347-401. 